\title{
Trichinellosis acquired in the United Kingdom
}

\author{
L. M. MILNE ${ }^{1 *}$, S. BHAGANI ${ }^{2}$, B. A. BANNISTER ${ }^{2}$, S. M. LAITNER ${ }^{1}$, \\ P. MOORE ${ }^{3}$, D. $\mathrm{EZA}^{4}$ AND P. L. CHIODINI ${ }^{5}$ \\ ${ }^{1}$ West Hertfordshire Health Authority, Tonman House, 63-77 Victoria Street, St Albans AL1 3ER \\ ${ }^{2}$ Royal Free Hospital, Pond Street, London NW3 2QG \\ ${ }^{3}$ The Maltings Surgery, 8 Victoria Street, St Albans AL1 3JB \\ ${ }^{4}$ Department of Histopathology, Rockefeller Building, University Street, London WC1E 6JJ \\ ${ }^{5}$ Hospital for Tropical Diseases, The Mortimer Market Centre, Capper Street, London WCIE $6 A U$
}

(Accepted 10 April 2001)

\section{SUMMARY}

An outbreak of trichinellosis that occurred in the United Kingdom is described. Members of four households consumed pork salami from northern Serbia, the Federal Republic of Yugoslavia. Eight cases of trichinellosis occurred. Clinical and laboratory features of the cases were typical with myalgia (7 cases), fever (6), headache (5), periorbital oedema (4), non-specific ST/T wave changes on electrocardiogram (3), Trichinella antibodies (6), eosinophilia (7) and raised serum creatine kinase (3). All recovered. Trichinella larvae were detected in the salami. During pre-travel counselling, travellers should be advised about possible risk from cured pork products which have been produced locally in Trichinella endemic areas.

\section{INTRODUCTION}

Trichinellosis is a zoonosis with a worldwide distribution [1]. Human trichinellosis is acquired by eating meat containing viable larvae of the nematode Trichinella, usually Trichinella spiralis [1, 2], and travellers are occasionally at risk [3, 4]. The first symptoms are usually abdominal pain and diarrhoea occurring in the first week after ingestion of larvae, as adult worms mature in the gastrointestinal tract [5]. Myalgia, fever and periorbital oedema occur after approximately 2-3 weeks, as new larvae migrate through the tissues and encyst in muscle $[2,5]$.

Pork has been an important source of human trichinellosis in Europe [1, 2, 6, 7] including Yugoslavia [8,9] and elsewhere [2, 3, 5, 10-12]. This has led to public health measures designed to decrease the risk of human and animal infection [2, 5, 6, 9-14].

There have been no reports of Trichinella affecting domestic animals or humans in the United Kingdom

\footnotetext{
* Author for correspondence.
}

since 1969 [6] prior to a preliminary communication $[15,16]$ about this outbreak. This contrasts with the situation in the Federal Republic of Yugoslavia (formerly Yugoslavia) where outbreaks have been described [8, 17]. We describe an outbreak of trichinellosis that occurred in the United Kingdom and originated from the Federal Republic of Yugoslavia.

\section{MATERIALS AND METHODS}

In November 1999 a United Kingdom resident, initially from Yugoslavia, returned home to England after visiting northern Serbia in the Federal Republic of Yugoslavia. The resident brought back 9 locally produced pork salamis, keeping 5 and distributing the remaining 4 as gifts to 3 other households. Five weeks later, a patient from one of the households (case 1) presented with muscle aches and fever to his general practitioner. The patient suspected trichinellosis because he was aware that the gift of salami had been obtained from a butcher whose pork products were 
Table 1. Clinical and laboratory findings of cases

\begin{tabular}{|c|c|c|c|c|c|c|c|}
\hline $\begin{array}{l}\text { Case } \\
\text { Number }\end{array}$ & Sex & $\begin{array}{l}\text { Age } \\
\text { (years) }\end{array}$ & $\begin{array}{l}\text { Incubation } \\
\text { period } \\
\text { (days) }\end{array}$ & $\begin{array}{l}\text { Duration } \\
\text { of symptoms } \\
\text { (days) }\end{array}$ & $\begin{array}{l}\text { Trichinella } \\
\text { IFAT* }^{*}\end{array}$ & $\begin{array}{l}\text { Highest } \\
\text { eosinophil } \\
\text { count } \\
\left(\times 10^{9} \text { per litre }\right) \dagger\end{array}$ & $\begin{array}{l}\text { Highest serum } \\
\text { creatinine } \\
\text { kinase (IU/l) }\end{array}$ \\
\hline 1 & $M \ddagger$ & 41 & 23 & 35 & 1 in 256 & $2 \cdot 1$ & 1400 \\
\hline 2 & $\mathrm{~F} \S$ & 37 & 25 & 31 & 1 in 128 & $1 \cdot 6$ & 711 \\
\hline 3 & M & 10 & 26 & 18 & 1 in 128 & $1 \cdot 7$ & 119 \\
\hline 4 & $\mathrm{~F}$ & 38 & 30 & 33 & Negative & $0 \cdot 2$ & 53 \\
\hline 5 & $\mathrm{~F}$ & 35 & 26 & 1 & 1 in 128 & $3 \cdot 0$ & 42 \\
\hline 6 & $\mathrm{~F}$ & 27 & 31 & 14 & 1 in 256 & $5 \cdot 1$ & 424 \\
\hline 7 & M & 43 & 5 & 7 & Not done & $4 \cdot 0$ & 115 \\
\hline 8 & $\mathrm{~F}$ & 26 & 26 & Few & 1 in 64 & $1 \cdot 0$ & 191 \\
\hline
\end{tabular}

* Indirect fluorescent antibody titre.

$\dagger$ International units per litre.

\$ Male.

$\S$ Female.

under investigation following a local outbreak of trichinellosis.

All persons who had eaten the salami and all children in those households were identified. A clinical history was taken and clinical examination including electrocardiography (ECG) and echocardiogram was performed. Laboratory investigations included serum Trichinella antibodies, peripheral eosinophil counts, serum and myocardial creatine kinase levels and serum alanine aminotransferase levels.

A case of trichinellosis was defined as a person who fulfilled the Centre for Disease Control criteria [5]. These were (1) Trichinella-positive muscle biopsy or a positive serological test for trichinellosis in a patient with one or more clinical symptoms compatible with trichinellosis (eosinophilia, fever, myalgia and periorbital oedema), or (2) in an outbreak, among clinical and epidemiologically associated cases, at least one person must meet criterion 1. Associated cases were defined by either a positive serological test result for trichinellosis or one or more clinical symptoms compatible with trichinellosis among persons who ate the epidemiologically implicated product [5].

All remaining salamis were obtained and sent for Trichinella examination.

\section{RESULTS}

Eight adults had eaten salami and seven of these had trichinellosis (Table 1). There was also an infected child (case 3) who denied eating salami. The clinical features were myalgia ( 7 cases), fever (self reported) (6), headache (5), periorbital oedema (4), peripheral oedema (2), nausea (2), rash (2), diarrhoea (1) and vomiting (1). Cases 1 and 4 described short episodes of retrosternal chest pain, associated with orthopnoea in case 4. Case 2 had palpitations. Cases 1, 2 and 4 had non-specific ST-T wave changes on ECG but normal myocardial creatine kinase levels. Five cases had raised serum alanine aminotransferase levels.

Six salami specimens were examined. Trichinella larvae were seen in one out of the five specimens that were examined by digestion. A sixth specimen, examined histologically, showed myofibres with several hyalinized cystic lesions containing cross-sections of tightly coiled parasites (Fig. 1).

\section{DISCUSSION}

In 1999, there were 555 cases of human trichinellosis in Serbia [18]. All were acquired by eating pork or wild boar that had not undergone veterinary inspection [18]. The pork product involved in our incident entered the UK unconventionally when a traveller carried salamis home and distributed them as gifts. We understand that our cases were part of an outbreak that was linked to 138 cases in Vojvodina province, Serbia and was one of 16 outbreaks that occurred in the province in 1999 [17]. Previous imported cases of trichinellosis within western Europe have been attributed to infection acquired in Yugoslavia [4]. Pre-travel counselling may be useful for prevention $[3,4]$ and we suggest that this should include advice about possible risk from cured pork products that have been produced locally in Trichinella endemic areas. 


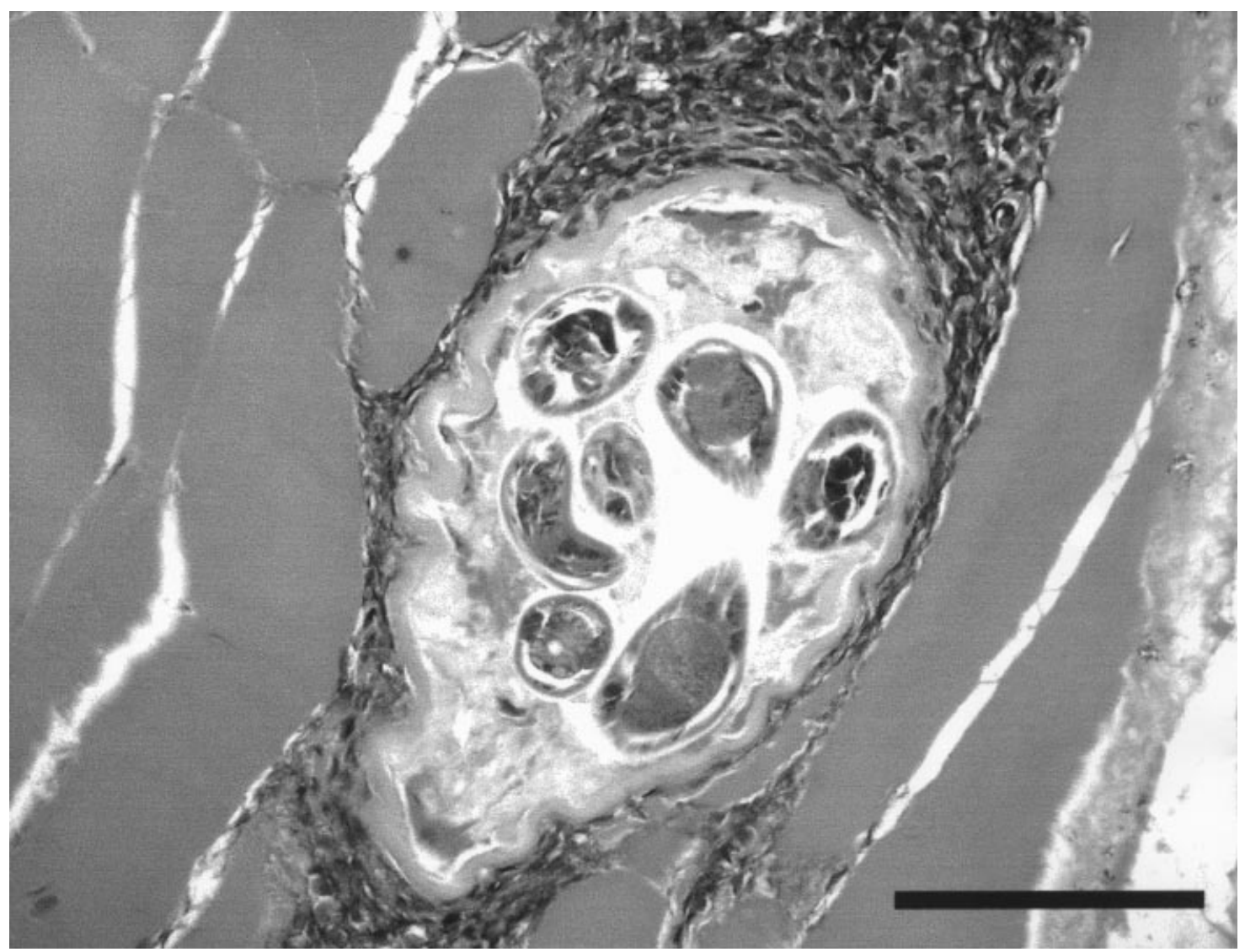

Fig. 1. Photomicrograph of a Trichinella spiralis larva encysted in muscle fibre and surrounded by inflammatory cells (haematoxylin and eosin stained; bar $=100 \mu \mathrm{m}$ ).

The symptoms and signs of our cases were mild and typical of those reported in trichinellosis $[1-5,12,19$, 20]. They occurred about 4 weeks after exposure (Table 1), in keeping with systemic migration of larvae [2]. It is interesting that four cases developed gastrointestinal symptoms about 1 month after exposure, as these usually occur earlier. Myalgia occurred in seven cases $(88 \%)$ and has affected up to $95 \%$ in some reports [19]. Three cases had evidence of significant myositis on the basis of raised serum creatine kinase levels; our upper limit for the normal value of serum creatine kinase was 190 international units per litre. Case one had the highest level and longest duration of symptoms. Non-specific ST-T wave changes, as reported elsewhere [19], were present in three of our cases. However, echocardiography and myocardial creatine kinase levels indicated that these cases did not have significant myocardial involvement. Six $(75 \%)$ of our cases had fever (self reported), as compared with $60-87 \%$ in other series $[3,5,19,20]$. Periorbital oedema affected four $(50 \%)$ of our cases, compared with $29-95 \%$ [3, 5, 19, 20] in other series. Trichinella antibodies were sought between 17 and 24 days after the onset of symptoms. Trichinella serology has often been negative in the early stages of infection [13] but 6 of the $7(86 \%)$ cases tested had Trichinella antibodies. Case 4 was tested 17 days after the onset of symptoms. Seven cases ( $88 \%$ ) had eosinophilia; our upper limit for the normal value for eosinophils was $0.5 \times 10^{9}$ per litre. All these, except one who was not tested, had serological evidence of trichinellosis. However, other series have shown discrepancies between cases who had eosinophilia and those who had serological evidence of trichinellosis [1].

All our patients recovered fully but in other cases variable clinical courses have been described [4]. In general, the severity of clinical features has been thought to parallel the number of larvae ingested [11]. Asymptomatic infection may occur when only a few larvae are ingested [11]. Diarrhoea, myositis, fever, periorbital oedema and prostration can occur after heavy exposure [4], and encephalitis, pulmonary involvement and myocarditis have all been described $[2,4]$. Trichinellosis may be fatal $[2,5]$. No trials of post-exposure prophylaxis have been published. However, in this outbreak, cases and those who had 
eaten salami were offered treatment with an antihelminthic drug in an effort to abort the development of mature adult worms in the gut during the incubation period. Drug treatment has not been shown to be effective in cases with established symptoms.

When available salamis were examined, Trichinella larvae and also features consistent with those of larvae encysted in myofibres or nurse cells [21] were seen (Fig. 1). The destruction of larvae in pork during curing relates to the salt concentration, drying temperature and drying time used [22]. Meat processors should be educated about precise curing methods required to destroy live larvae in pork meat [13]. However, a difficulty is that no parameters achieved by curing have been shown to correlate definitively with larva inactivation [10]. Our cases are consistent with pork products such as smoked meat or home-made sausage being the main source of human infections in Yugoslavia [9]. In other countries pork sausage consumption has been associated with human trichinellosis [1, 12]. However these latter reports stressed the dangers of consuming inadequately cooked pork $[1,12]$ and it seems that cured ready-toeat products such as salami were not involved.

Countries including the United Kingdom and Yugoslavia have measures in place that would normally prevent and control porcine trichinellosis. These include legislation $[6,10,11,14]$, education about good pig management practices [10, 11], methods to identify trichinellosis in infected herds [10, 14], safe production practices [10] and public awareness [8]. A problem is that the majority of Trichinella infections in domestic pigs are well below the levels of detection that can be achieved by meat inspection, i.e. less than one larva per gram of tissue [10] and low level pig infections have probably been responsible for many subclinical or undiagnosed human infections [10].

We do not know what preventative and control measures were applied to the pork involved in our outbreak. Usually, only pigs grazing in wild areas or reared on small family farms by traditional practices are implicated $[6,9,11,23]$. This is partly due to close contact with sylvatic hosts of trichinellosis [23]. Traditional pig husbandry arrangements in Yugoslavia [9] make control of trichinellosis challenging. Over $80 \%$ of arable land has been owned by small farmers and over $80 \%$ of livestock has been raised on privately owned farms [8]. In 1999, just over two million swine were slaughtered and inspected and, of these, $2552(0 \cdot 12 \%)$ had trichinellosis [17]. Despite difficulties [14, 23], progress in trichinellosis control has been made in the Federal Republic of Yugoslavia. Reporting of outbreaks should contribute to more effective prevention and control [8] and more sensitive methods to detect larvae in pig meat are now in use [14]. However, human cases linked to locally produced salami from the Federal Republic of Yugoslavia may present elsewhere in Europe, as occurred in this outbreak.

Trichinellosis should be considered in the differential diagnosis of persons who have eaten locally produced cured pork products from a Trichinella endemic area and who develop gastrointestinal symptoms, myalgia, fever, oedema, or eosinophilia.

\section{REFERENCES}

1. Tiberio G, Lanzas G, Galarza MI, Sanchez J, Quilez I, Martinez Artola V. Short report: an outbreak of trichinosis in Navarra, Spain. Am J Trop Med Hyg 1995; 53: 241-2.

2. Murrell KD, Bruschi F. Clinical trichinellosis. In: Tsien Sun, ed. Progress in clinical parasitology. Boca Raton: CRC Press, 1994: 117-50.

3. McAuley JB, Michelson MK, Schantz PM. Trichinella infection in travelers. J Infect Dis 1991; 164: 1013-6.

4. Clausen MR, Meyer CN, Krantz T, et al. Trichinella infection and clinical disease. Q J Med 1996; 89: 631-6.

5. Moorhead A, Grunenwald PE, Dietz VJ, Schantz PM. Trichinellosis in the United States, 1991-1996: declining but not gone. Am J Trop Med Hyg 1999; 60: 66-9.

6. Pozio E. Trichinellosis in the European Union: epidemiology, ecology and economic impact. Parasitol Today $1998 ; \mathbf{1 4}: 35-8$.

7. Desenclos J. Pork related trichinellosis: emergence of a new mode of transmission? Eurosurveillance 1999; 4: 77.

8. Cuperlovic K. Current status of food-borne parasitic zoonoses - Eastern Europe. Southeast Asian J Trop Med Pub Health 1991; 22 Suppl 4: 72-7.

9. Cuperlovic K. Epidemiology of swine trichinellosis in Yugoslavia. Southeast Asian J Trop Med Pub Health 1991; 22 Suppl 4: 308-11.

10. Gamble HR. Parasites associated with pork and pork products. Rev Sci Tech Off Int Epiz 1997; 16: 496-506.

11. Bailey TM, Schantz PM. Trends in the incidence and transmission patterns of trichinosis in humans in the United States: comparisons of the periods 1975-1981 and 1982-1986. Rev Infect Dis 1990; 12: 5-11.

12. McAuley JB, Michelson MK, Schantz PM. Trichinosis surveillance, United States. 1987-1990. CDC Surveillance Summaries. MMWR 1991; 40: 35-42. 
13. Greenbloom SL, Martin-Smith P, Isaacs S, et al. Outbreak of trichinosis in Ontario secondary to the ingestion of wild boar meat. Can J Public Health 1997; 88: $52-6$.

14. Dordevic M. Detection of Trichinella by various methods in Yugoslavia. Southeast Asian J Trop Med Pub Health 1991; 22 Suppl 4: 326-8.

15. CDSC. Outbreak of trichinellosis in South East England. CDR Wkly 2000; 10: 9, 12.

16. Bhagani S, Burn M, Bannister B, Milne L. Outbreak of trichinellosis in south east England. Eurosurveillance Weekly 2000; http://www.eurosurv.org/2000/ 000113.html.

17. Cuperlovic, K. Report of trichinellosis from Yugoslavia. International commission on trichinellosis. News. http://www.krenet.it/ict/Yugo.html.

18. Cuperlovic K, Djordjevic M, Pavlovic S, SofronicMilosavljevic L. Present status of trichinellosis in Yugoslavia: Serbia. Xth international conference on trichinellosis (ICT10). 20-24 August 2000. http:// wwwusers.imaginet.fr/ dupouyca/abstracts.html.

19. Lazarevic AM, Neskovic AN, Goronja M, et al. Low incidence of cardiac abnormalities in treated trichinosis: a prospective study of 62 patients from a single-source outbreak. Am J Med 1999; 107: 18-23.

20. Cui J, Wang ZQ, Wu F, Jin XX. Epidemiological and clinical studies on an outbreak of trichinosis in central China. Ann Trop Med Parasitol 1997; 91: 481-8.

21. Despommier DD. Trichinella spiralis and the concept of niche. J Parasitol 1993; 79: 472-82.

22. Smith HJ, Messier S, Tittiger F. Destruction of Trichinella spiralis spiralis during the preparation of the 'dry cured' pork products proscuitto, proscuittini and Genoa salami. Can J Vet Res 1989; 53: 80-3.

23. Marinculic A, Rapic D, Brglez J, Dzakula N, Stojiljkovic D. Epidemiological survey of trichinellosis in Yugoslavia. Southeast Asian J. Trop Med Pub Health 1991; 22 Suppl 4: 302-7. 